\title{
Choosing versus rejecting: Why some options are both better and worse than others
}

\author{
ELDAR SHAFIR \\ Princeton University, Princeton, New Jersey
}

\begin{abstract}
A previously unobserved pattern of choice behavior is predicted and corroborated. In line with the principle of compatibility, according to which the weighting of inputs is enhanced by their compatibility with output, the positive and negative dimensions of options (their pros and cons) are expected to loom larger when one is choosing and when one is rejecting, respectively. Subjects are presented with pairs of options, one of which-the enriched option-has more positive as well as more negative dimensions than does the other, impoverished, option. Because positive dimensions are weighted more heavily in choosing than in rejecting, and negative dimensions are weighted more heavily in rejecting than in choosing, the enriched option tends to be chosen and rejected relatively more often than the impoverished option. These findings are extended to nonbinary decision problems, and their implications for the rational theory of choice and for everyday decisions are discussed.
\end{abstract}

Decision theory is concerned with the behavior of people who are faced with the problem of choosing among options. Choices are commonly assumed to reflect underlying preferences, which are expected to satisfy a number of basic conditions. Most importantly, the classical theory of preference assumes that each individual has a well-defined preference order (or a utility function) over any set of options. Each option has some personal value, or utility, for the decision maker, a well-established position in his/her preference ordering: If the person prefers option $X$ over option $Y$, he/she should not also prefer option $Y$ over option $X$ (von Neumann \& Morgenstern, 1947). In addition, if an individual has clear and stable preferences, these should be invariant across normatively equivalent methods of assessing preference and across logically equivalent ways of describing the options.

Recent studies of decision making indicate that the foregoing assumptions do not always hold, because people tend not to have well-defined values and preferences. Making decisions is often hard, because we do not know how to trade off one attribute (e.g., salary) against another (e.g., leisure), how to predict the pleasure or pain of future consequences, or, for that matter, what exactly matters to us most (Goldstein, 1990; Kahneman \& Snell, 1990; March, 1978; Slovic, Fischhoff, \& Lichtenstein, 1982). Hence, we often arrive at a decision problem not with well-established and clearly ranked preferences, but rather with the need to determine our preferences as a result of having to decide. Preferences, it turns out, are

This research was supported by US Public Health Service Grant 1R29-MH46885 from the National Institute of Mental Health. The paper has benefitted from the comments of Philip Johnson-Laird, Dale Miller, Dan Osherson, Amy Pierce, Robert Proctor, Edward Smith, Amos Tversky, and three anonymous reviewers. Correspondence should be addressed to E. Shafir, Department of Psychology. Princeton University, Princeton, NJ, 08544 (e-mail: eldar@clarity.princeton.edu). actually constructed - not merely revealed-during their elicitation. And the construction of preferences appears to be sensitive to various aspects of the decision problem. Work on framing (Tversky \& Kahneman, 1986) and on methods of elicitation (Payne, 1982; Tversky, Sattath, \& Slovic, 1988) has shown preferences to be remarkably sensitive to the ways in which options are described (e.g., in terms of gains or losses) and to the methods through which preferences are elicited (e.g., through judgment or choice). Decisions are often reached by focusing on considerations that justify the selection of one option over others (Simonson, 1989; Slovic, 1990; Tversky \& Shafir, 1992; see Shafir, Simonson, \& Tversky, in press, for discussion). Different frames, contexts, and elicitation procedures highlight different aspects of the options and bring forth different considerations, which often give rise to inconsistent decisions.

A general mechanism underlying the construction of preferences is captured by the compatibility principle. According to this principle, some tasks are easier to perform than others and some stimulus components are more salient than others because of the particular sets of stimuli and responses that are being used, and because of the ways in which these stimuli and responses interact with each other. The significance of the compatibility between input and output has long been recognized by students of human perceptual and motor performance. In their investigations of stimulus-response compatibility, these researchers have observed, for example, that responses to visual displays of information, such as an instrument panel, will be faster and more accurate if the response structure is compatible with the arrangement of the stimuli (Fitts \& Seeger, 1953; Wickens, 1984). Thus, a square array of four burners on a stove is easier to control with a corresponding square array of knobs rather than a linear array. Similarly, the response to a pair of lights is faster 
and more accurate if the left light is assigned to the left key and the right light to the right key. Beyond spatial organization, stimulus-response compatibility has been evoked, for example, to account for the fact that a pointing response is faster than a vocal response when the stimulus is visual, whereas a vocal response is faster than pointing when the stimulus is auditory (Brainard, Irby, Fitts, \& Alluisi, 1962). The rationale for such effects is that a translation stage intervenes between the presentation of stimuli and the selection of responses: the greater the compatibility between stimuli and responses, the less the time that is required and the lower the likelihood of error. Compatibility between stimulus and response ensembles has been proposed to account for results obtained in a wide variety of performance tasks (see, e.g., Kornblum, Hasbroucq, \& Osman, 1990; see also Proctor \& Reeve, 1990, for related discussions).

Recent work in judgment and decision making has extended the notion of compatibility and proposed that the weight of certain stimulus attributes in judgment or in choice is enhanced by their compatibility with the response scale (Slovic, Griffin, \& Tversky, 1990; Tversky et al., 1988). The rationale for this principle is that the specific nature of the response scale tends to focus attention on the compatible features of the stimulus. For example, setting the price of a gamble is likely to emphasize payoffs more than probabilities because both the price and the payoffs are in monetary units (e.g., dollars). When a stimulus attribute and the response do not match, additional mental operations are required to map one into the other. As with the spatial mapping between stimulus and response ensembles, noncompatibility between a stimulus attribute and the response scale requires additional mental operations, which often increase effort and error, and reduce impact.

The principle of scale compatibility has recently been invoked to explain a number of phenomena in judgment and decision making. Consider, for example, the wellknown preference reversal phenomenon (Slovic \& Lichtenstein, 1983; Tversky, Slovic, \& Kahneman, 1990). Preference reversal typically occurs when subjects choose a lottery that offers a greater chance to win over another that offers a higher payoff, but then assign a higher price to the lottery offering the higher payoff than to the one with the greater chance to win. This pattern of preferences, which violates classical decision theory, has been observed in numerous experiments, including a study involving professional gamblers and conducted on the floor of a Las Vegas casino (Lichtenstein \& Slovic, 1973). Because the prices of lotteries are expressed in dollars, scale compatibility implies that the payoffs, which are expressed in the same units, will be weighted more heavily in pricing than in choice. Hence, the high-payoff lottery will be favored more in pricing than in choice, which predicts the preference reversal phenomenon.

Slovic et al. (1990) present various other studies, ranging from predictions of market value to time preferences, wherein the weight of a stimulus attribute is shown to be enhanced by its compatibility with the response scale. In one study, for example, subjects were presented with pairs of hypothetical students who had jointly taken two courses, and whose grades in one course and ranks in the other were provided: one had a higher grade in one course and the other a higher rank in the second. Half the subjects were asked to predict which student would achieve a higher grade in a third course, and the remaining subjects were asked to predict which student would achieve a higher rank. Compatibility implies that the relative weight of grades to ranks will be higher for the group that predicts grades than for the group that predicts ranks. As predicted, the student with the higher grade was expected to perform better $56 \%$ of the time by the grade group and only $49 \%$ of the time by the rank group ( $p<$ .05). Finally, evidence for scale compatibility has also been reported by Schkade and Johnson (1989), who, in a computer-controlled experiment, were able to show that subjects spent more time on, and thereby presumably focused more attention on, the stimulus components that were most compatible with the scale of the response mode. Naturally, compatibility effects tend to be mild, and limited in their ability to influence decision. When one option overwhelmingly surpasses another, a slight difference in the relative weighting of dimensions is unlikely to alter a person's choice. Yet in some instances, when the decision is difficult and the options are of otherwise comparable worth, compatibility can have a decisive effect on the determination of preference.

In what follows, a new pattern of choices is described that is consistent with the notion of compatibility. Whereas scale compatibility is a function of the correspondence between stimulus-attribute scales and the response scale, the present proposal addresses the compatibility between the reasons available for choosing or rejecting an option and the particular task at hand. In particular, it is argued that options' positive and negative features are weighted differentially, depending on whether the options are being chosen or rejected. Options' advantages provide compelling reasons for choosing, and thus make choices easier to determine and justify to oneself and to others. Options' disadvantages provide natural reasons for rejecting, and thus make rejection easier to determine and justify. Considerations of compatibility suggest that positive dimensions will be weighted more in choosing than in rejecting, whereas negative dimensions will be emphasized more in rejecting than in choosing. In what follows, this simple prediction is shown to generate some new and counterintuitive results. Because there is neither a formal definition of compatibility nor a general procedure for its assessment, the analysis remains informal and incomplete. The same is true about the application of the principle of compatibility to perceptual and motor performance. However, just as a control panel is clearly more compatible with some information displays than with others, so can the compatibility ordering in the context of choice be sufficiently clear to allow experimental investigation. To elucidate the logic that guides our prediction, we begin by 
drawing an analogy to another, well-known, psychological phenomenon. We then present a number of studies that document the predicted discrepancies between choosing and rejecting, and we conclude with a discussion of the findings and their implications.

\section{AN ANALOGY AND THE PREDICTION}

In his contrast model of similarity, Tversky (1977) presents a set-theoretical approach to similarity, in which objects are represented as collections of features, and in which similarity between objects is expressed as an increasing function of the features that they have in common, and a decreasing function of the features that each object has and the other does not. Judgments of dissimilarity between objects are commonly assumed to be complementary to similarity judgments: dissimilarity is an increasing function of distinctive features and a decreasing function of common features. Tversky suggests, however, that because of a change in focus, judgments of similarity and dissimilarity may not be mirror images. In the assessment of similarity between stimuli, the subject-as compatibility suggests-may attend more to their common features, whereas in the assessment of difference, the subject may attend more to their distinctive features. As a result, common features are predicted to loom larger in judgments of similarity than in judgments of dissimilarity, whereas distinctive features are predicted to loom larger in judgments of dissimilarity than in judgments of similarity. This leads to a straightforward but surprising prediction: A pair of objects with many common and many distinctive features could be judged as more similar, as well as more dissimilar, than another pair of objects with fewer common and fewer distinctive features. Tversky and Gati (1978) observed this pattern in the comparison of pairs of well-known countries with pairs of countries that were less well known. For example, most subjects in the similarity condition selected East Germany and West Germany (the prominent pair) as more similar to each other than Ceylon and Nepal (the nonprominent pair), whereas most subjects in the dissimilarity condition selected East Germany and West Germany as more different from each other than Ceylon and Nepal. Related findings are reported in Medin, Goldstone, and Gentner (1990). If similarity and difference are complementary, the sum of percentages of those who choose a pair as more similar and those who choose it as more different should equal 100 . Instead, the average share obtained by Tversky and Gati for the more prominent pairs (113.5) was significantly greater than 100 .

With Tversky's similarity-difference example in mind, let us return to choice. In particular, consider having to choose one of two options, or alternatively, having to reject one of two options. Logically, the tasks are identical. According to classical decision theory, in a binary choice situation it should not matter whether people are asked which option they prefer, or which they would like to reject. If people prefer the first they will reject the sec- ond, and vice versa. Naturally, the more positive features an option has, the more likely it is to be chosen and the less likely to be rejected; conversely, the more negative features it has, the more likely it is to be rejected and the less likely to be chosen. Let each option $a$ be characterized by a set of positive and a set of negative features, denoted $A+$ and $A-$, respectively, and assume a value function, $v$, defined on these sets of features. Thus, $a$ 's overall value increases with $v(A+)$ (a positive number) and decreases with $v(A-)$ (a negative number). The relative weights assigned to positive and negative features when one is choosing, however, may differ from those assigned when one is rejecting. To the extent that people base their decisions on reasons for and against the options under consideration, they are likely to focus on reasons for choosing an option when asked to choose and they are likely to focus on reasons for rejecting an option when asked to reject. After all, one does not prefer an option because of its relative disadvantages, nor does one reject an option because of its advantages. Thus, the positive features of options (their pros) are expected to loom larger in choosing, whereas the negative features of options (their cons) are expected to weigh more heavily in rejecting. Assume, therefore, that there exist nonnegative constants $\delta$ and $\lambda$ such that

$a$ is chosen over $b$

$$
\text { iff } v\left(A^{+}\right)+\delta v\left(A^{-}\right)>v\left(B^{+}\right)+\delta v\left(B^{-}\right),
$$

and

$$
\begin{aligned}
& a \text { is rejected in favor of } b \\
& \quad \text { iff } v\left(A^{+}\right)+\lambda v\left(A^{-}\right)<v\left(B^{+}\right)+\lambda v\left(B^{-}\right) .
\end{aligned}
$$

Thus, $\delta$ and $\lambda$ reflect the relative weights of negative features in the decisions to choose and to reject, respectively. Note that if $\delta$ is very small, preference is essentially determined by the positive features, and if $\lambda$ is very large, preference is determined primarily by the negative features. Consequently, we may obtain a situation wherein $a$ is chosen over $b$, and wherein $a$ is also rejected in favor of $b$, whenever

$$
v\left(A^{+}\right)>v\left(B^{+}\right) \text {and } v\left(A^{-}\right)<v\left(B^{-}\right) .
$$

That is, if-in line with compatibility-positive features are weighted more heavily in choosing than in rejecting, an option with greater positive and greater negative features could be chosen over, as well as rejected in favor of, another option with lesser positive and lesser negative features. We shall investigate this prediction in the following section. ${ }^{1}$

\section{TESTS OF CHOOSING VERSUS REJECTING}

\section{Binary Problems}

The problems in this section were presented to Princeton University undergraduate volunteers, who were paid for their participation. The problems, two or three per subject on the average, were arbitrarily inserted among 
numerous other, unrelated problems in a booklet format. Each problem presents a choice between two options: an option with more positive and more negative features (henceforth, the enriched option) and an option with fewer positive and fewer negative features (henceforth, the $\mathrm{im}$ poverished option). By way of manipulation checks, for each of the problems that follow, at least $85 \%$ of an independent group of subjects $(N=26)$ chose the enriched option as the option "that has more reasons for and against it" than the competing, impoverished option $(p<.001$ in all cases). Each problem was presented to two groups of subjects: one group was asked to choose (award or indicate a preference for) an option; the other group was asked to reject (deny or give up) an option.

Let $\Pi_{c}$ and $\Pi_{r}$ denote, respectively, the percentage of subjects who choose and who reject a particular option. If choosing and rejecting are complementary (i.e., $\delta=\lambda$ ), the sum $\Pi_{c}+\Pi_{r}$ should equal 100 . According to the rationale outlined in the previous section, on the other hand, we should expect the enriched option to be chosen and rejected more often than the impoverished option. According to this prediction, the value of $\Pi_{c}+\Pi_{r}$ should be greater than 100 for the enriched option and, consequently, smaller than 100 for the impoverished option.

Consider the following problem, which was presented in two versions that differed only in the bracketed questions. One half of the subjects received the award version; the other half, the deny version. (In all the problems that follow, the enriched option appears last, although the order presented to subjects was counterbalanced.)

\section{Problem $1(N=170)$}

Imagine that you serve on the jury of an only-child sole-custody case following a relatively messy divorce. The facts of the case are complicated by ambiguous economic, social, and emotional considerations, and you decide to base your decision entirely on the following few observations. [To which parent would you award sole custody of the child?/ Which parent would you deny sole custody of the child?]

$\begin{array}{llll}\text { Parent A } & \begin{array}{l}\text { average income } \\ \text { average health } \\ \text { average working hours } \\ \text { reasonable rapport with the } \\ \text { child } \\ \text { relatively stable social life } \\ \text { Parent B }\end{array} & & \\ \text { above-average income } \\ \text { very close relationship with } \\ \text { the child } \\ \text { extremely active social life } \\ \text { lots of work-related travel } \\ \text { minor health problems }\end{array}$

Parent A, the impoverished option, is quite plain, with no striking positive or negative features. There are no particularly compelling reasons to award Parent A custody of the child, nor are there good reasons to deny him/her. Parent B, the enriched option, on the other hand, has good reasons to be awarded custody (such as a very close relationship with the child and a high income), but also good reasons to be denied sole custody (such as health problems and extensive absences due to travel). To the right of the options are the percentages of subjects who chose to award and to deny custody to each of the parents. Parent $B$ is the modal choice both for being awarded custody of the child and for being denied it. As predicted, the value of $\Pi_{c}+\Pi_{I}$ for Parent $B(64+55=119)$ is significantly greater than the 100 that we would expect if choosing and rejecting were complementary $(z=2.48$, $p<.02$ ). Because he/she presents better reasons for both decisions, note that Parent B's likelihood of obtaining custody is significantly greater when subjects decide whom to award than when they ask themselves whom to deny ( $64 \%$ vs. $45 \%, z=2.49, p<.02$ ).

As another example, consider the following problem, in which half the subjects received the prefer and the other half the cancel version.

$$
\text { Problem } 2(N=172)
$$

Prefer:

Imagine that you are planning a week vacation in a warm spot over spring break. You currently have two options that are reasonably priced. The travel brochure gives only a limited amount of information about the two options. Given the information available, which vacation spot would you prefer? Cancel:

Imagine that you are planning a week vacation in a warm spot over spring break. You currently have two options that are reasonably priced, but you can no longer retain your reservation for both. The travel brochure gives only a limited amount of information about the two options. Given the information available, which reservation do you decide to cancel?

$\begin{array}{llll}\text { Spot A } \quad \begin{array}{ll}\text { average weather } \\ \text { average beaches } \\ \text { medium-quality hotel }\end{array} & 33 \% & 52 \% \\ & \begin{array}{l}\text { medium-temperature water } \\ \text { average nightlife }\end{array} & & \\ \text { Spot B } \quad \begin{array}{l}\text { lots of sunshine } \\ \text { gorgeous beaches } \\ \text { and coral reefs } \\ \text { ultra-modern hotel } \\ \text { very cold water } \\ \text { very strong winds } \\ \text { no nightlife }\end{array} & 67 \% & 48 \% \\ \end{array}$

The information regarding the two spots is typical of the kind of information we have available when deciding where to take our next vacation. While Spot A seems unremarkable yet unobjectionable on all counts, Spot B has certain features-like the gorgeous beaches, plenty of sunshine, and the modern hotel - that make it clearly preferable to many subjects, but it has other features-like the cold water, the winds, and a lack of nightlife-that make many subjects decide to reject it. The result is that Spot B's share of being preferred and rejected exceeds the expected $100\left(\Pi_{\mathrm{c}}+\Pi_{\mathrm{r}}=115, z=2.05, p<.05\right)$. These results demonstrate that options are not simply ordered according to their attractiveness, with the more attractive selected and the less attractive rejected. Instead, it appears that the relative importance of options' strengths 
and weaknesses varies with the nature of the task. The gorgeous beaches play a greater role when we choose than when we reject, and the lack of nightlife plays a more central role when we reject than when we choose. As a result, we are significantly more likely to end up in Spot B when we ask ourselves which spot we prefer than when we contemplate which reservation to cancel $(67 \%$ vs. $52 \%, z=2.0, p<.05$ ).

Similar effects may be observed not only when the decision is to choose or to reject but, for example, when we simply need to decide which of two options to opt for first, and which to leave for later. Four hundred and twenty-four undergraduates were presented with a description of two courses at a time when they were selecting their next semester's schedule:

\section{Problem 3}

Course $\mathrm{X}$ is considered an average course, with a reasonable reading list, and with an average work load.

Course $\mathrm{Y}$ has an extremely interesting reading list and is taught by a professor who is supposed to be very good. It has the reputation of a tough course, slow-going at times, and it meets more hours per week than the usual.

The subjects were asked to assume that they would eventually need to take both courses, but that one would be taken in the coming semester and the other at some later time. Half the subjects decided which course to take immediately, and the other half decided which course to leave for later. Course $\mathrm{X}$, the impoverished option, presents no compelling reason either to take it immediately, or to postpone it until a later point. Course $Y$, the enriched option, on the other hand, should be taken now since the reading list, which is terrific, could change, and the professor who is excellent could one day leave. Of course, there are good reasons to postpone it too; it is tough and it requires extra time. Students were significantly more likely to take Course $\mathrm{Y}$ in the coming semester when they were deciding which course to take than when they were deciding which to postpone $(75 \%$ vs. $65 \%, z=2.25, p<.05$ ). As predicted, Course Y's total share of being taken and postponed significantly exceeded that of Course $X\left(\Pi_{c}+\Pi_{r}=75+35=110, z=\right.$ $2.16, p<.05)^{2}$

Alternative accounts. Neither anticipated regret (Bell, 1982; Loomes \& Sugden, 1982) nor loss aversion (Tversky \& Kahneman, 1991) suffice to account for the present findings. Regret is commonly considered a function of what we have relative to what we could have had. Loss aversion-the notion that losses loom larger than gainsgenerally implies that losing the option we want most will hurt more than losing an option we want less. While anticipated regret and loss aversion constitute important aspects of the psychology of choice, both predict that if we prefer to have one option, we will prefer to lose the other. ${ }^{3}$

The preceding findings could result from subjects' confusion when making decisions in what may be the less natural frame. For example, subjects who clearly prefer
Option X may find it confusing when asked to reject one, and may erroneously reject Option $X$, eventually endow. ing it with more than its fair share of selections and rejections. To explore this possibility, another 244 subjects were presented with Problems 1 and 2 and were asked, upon making their decision, to write down their reasons for making that decision. Half the subjects received the choose (or award) version of the two problems, the other half the cancel (or deny) versions. The results of Problem 1 were in the predicted direction but failed to reach statistical significance $\left(\Pi_{\mathrm{c}}+\Pi_{\mathrm{r}}=55+53=108, p=\right.$ .20 ), whereas the data of Problem 2 replicated the previous findings $\left(\Pi_{c}+\Pi_{\mathrm{r}}=63+53=116, p<.05\right)$. Two judges, blind to the present investigation, were then asked to sort subjects' responses according to whether their stated reasons were in line with their indicated preferences. A subject was labeled inconsistent if he/she chose Option $\mathrm{X}$ while providing reasons that indicated an intention to reject that option, or if he/she rejected Option $X$ while giving reasons for choosing it. The judges agreed on over $90 \%$ of the subjects, and the few disagreements were resolved by discussion. Across both problems, 9\% of the subjects were judged clearly or possibly inconsistent, their data were removed, and the analyses were repeated. This had little effect: Problem 1 retained the predicted direction $\left(\Pi_{c}+\Pi_{r}=107\right)$ without reaching statistical significance, while the data of Problem 2 confirmed earlier findings $\left(\Pi_{\mathrm{c}}+\Pi_{\mathrm{r}}=113, p<.05\right)$. Note that these data include only subjects who provided consistent justification for their choices. Although confusion may contribute to the choose-reject discrepancy in certain situations, it cannot account for these results.

A simple recipe: Negative versus no negative features. Consider two simple lotteries. One offers a lessthan-certain chance to win $\$ 50$, and otherwise, nothing; the other offers a greater chance to win more than $\$ 50$, and otherwise a small loss, say $\$ 10$. Notice that there is nothing unattractive about the first lottery (you can only win), ${ }^{4}$ but that there is the unattractive possibility of a $\$ 10$ loss in the second. This suggests a simple recipe for constructing pairs of enriched and impoverished options that will yield unequal shares of $\Pi_{c}+\Pi_{r}$. First, create an enriched option by endowing it with a negative component while the impoverished option is accorded none. To the extent that negative features loom large when options are rejected, the enriched option's rate of rejection should be comparatively high. Now, its positive component may be increased so as to make it the modal choice. Consider the following two problems, created according to this recipe, each presented to half the subjects in a choice version and to the other half in a rejection version.

Choose

Imagine that you were invited to play one of the following two lotteries. Which one would you prefer?

Give up

Imagine that you owned tickets to play the following two lotteries, but had to return one. Which one would you prefer to give up? 


\begin{tabular}{|c|c|c|c|}
\hline \multicolumn{4}{|c|}{ Problem $4(N=279)$} \\
\hline & & Choose & Give up \\
\hline Lottery 1: & $\begin{array}{l}\text { You have a } 50 \% \text { chance to } \\
\text { win } \$ 50 \text {, otherwise nothing. }\end{array}$ & $25 \%$ & $50 \%$ \\
\hline Lottery 2: & $\begin{array}{l}\text { You have an } 80 \% \text { chance to } \\
\text { win } \$ 150 \text {, and a } 20 \% \text { chance } \\
\text { to lose } \$ 10 \text {. }\end{array}$ & $75 \%$ & $50 \%$ \\
\hline \multicolumn{4}{|c|}{ Problem $5(N=278)$} \\
\hline Lottery 1: & $\begin{array}{l}\text { You have a } 20 \% \text { chance to } \\
\text { win } \$ 50 \text {, otherwise nothing. }\end{array}$ & $23 \%$ & $60 \%$ \\
\hline Lottery 2 : & $\begin{array}{l}\text { You have a } 60 \% \text { chance to } \\
\text { win } \$ 100 \text {, and a } 40 \% \text { chance } \\
\text { to lose } \$ 5 \text {. }\end{array}$ & $77 \%$ & $40 \%$ \\
\hline
\end{tabular}

As predicted, the enriched lottery's share of $\Pi_{c}+\Pi_{r}$ exceeds 100 in both cases $(z=4.12$ and 2.83 , respectively, $p<.005$ in both cases.) While the greater chance to win a large amount leads an average of $76 \%$ of the subjects to choose the enriched lottery, the unparalleled possibility of a loss leads an average of $45 \%$ of the subjects to reject it.

These two problems were replicated in a within-subject design. Two hundred and forty-eight subjects received both the choice and the rejection versions of these problems. Half the subjects received both versions of Problem 4; the other half both versions of Problem 5. The two versions appeared in a booklet, separated by numerous unrelated problems in between, with their order of occurrence counterbalanced across subjects. Because there were no significant differences between problems or orders, the data were combined. We call a subject consistent if, having chosen one lottery, he/she then rejects the other, and vice versa. A subject is inconsistent if he/she both chooses and rejects the same lottery. Whereas a standard analysis based on error predicts that inconsistent subjects will be roughly equally distributed among the two options, the present thesis predicts that a majority of inconsistent subjects will have both chosen and rejected the enriched rather than the impoverished option. Averaged over problems, $22 \%$ of the subjects exhibited inconsistent preferences (24\% and $20 \%$ for Problems 4 and 5 , respectively). This corresponds quite well to the inconsistency rate implied by the between-subject manipulations above. More importantly, in line with the compatibility hypothesis, a significant majority of inconsistent subjects chose and rejected the enriched rather than the impoverished lottery $(74 \%$ vs. $26 \%$, p $<.001)$.

Naturally, the preceding recipe for constructing enrichedimpoverished pairs applies not only to monetary lotteries. Consider, for example, the following hypothetical problem, in which half the people were asked to choose and the other half to give up an ice-cream flavor.

$$
\text { Problem } 6(N=359)
$$

\section{Choose:}

You go to your favorite ice-cream parlor, and have to decide between two flavors: Flavor A is good; Flavor B is excellent, but is high in cholesterol. Which do you choose?
Give up:

You go to your favorite ice-cream parlor, and select two flavors: Flavor A is good; Flavor B is excellent. but is high in cholesterol. You then realize that you can only afford one. Which do you choose to give up?

$\begin{array}{ccc} & \text { Choose } & \text { Give up } \\ \text { Flavor A } & 28 \% & 55 \% \\ \text { Flavor B } & 72 \% & 45 \%\end{array}$

When they finally make it to their favorite ice-cream parlor, most people opt for their favorite flavor even if it entails a less than perfectly healthy snack; but when they have to forfeit a flavor, the fact that one is less healthy constitutes for many subjects a good reason to reject it in favor of the other, good and unobjectionable, flavor. As a result, the excellent flavor's high cholesterol content looms larger when it is rejected than when it is chosen, causing this flavor to obtain more than its fair share of selections and rejections $(z=3.22, p<.001)$. Note, incidentally, the obvious implications for a healthy diet: subjects were significantly more likely to consume the unhealthy (but more exciting) flavor when they focused on which flavor to choose than when they contemplated which flavor to reject.

Accentuating rejection. We generally tend to formulate and think of our decisions in terms of choosing rather than rejecting. A majority (59\%) of a group of people we interviewed $(N=80)$ reported often paraphrasing the question "Which of the options do you prefer to give up?" into the question "Which of the options do you prefer?" (and then giving up the other option), while many fewer (14\%) reported often paraphrasing the questions in the opposite direction. The greater popularity of the choose formulation implies that when asked to reject, a nonnegligible proportion of people will nonetheless entertain the act of choosing, whereas, asked to choose, fewer consider the act of rejecting. In terms of the compatibility principle, this implies a greater reliance on the positive features in choosing than on the negative features in rejecting. This asymmetry is consistent with a recurring trend in our results so far, in which the distribution of preferences in the reject condition is closer to parity than in the choose condition. The greater tendency to rely on positive rather than negative features may be due in part to the fact that we tend to associate choice with a search for "positive" outcomes; less frequently (especially in experimental settings) do we feel condemned to choose among undesirable alternatives. The foregoing choices, between, for example, monetary gambles, vacations, and ice creams, were all generally desirable and thus more likely to be perceived as involving selections than rejections, thereby emphasizing the positive dimensions. Other decisions, however, are likely to accentuate the negative dimensions. Having to decide between political candidates that one dislikes, for example, may be perceived as trying to avoid the worst of two evils: we may be more invested in rejecting the more objectionable candidate than in choosing the candidate that we oppose less. In this vein, 
consider the following choice between two political candidates. Half the subjects were asked which candidate they would vote for, and the other half which candidate they would not vote for. ${ }^{5}$

$$
\text { Problem } 7(N=398)
$$

Imagine that you are voting for the president of your town council. You are now considering two final candidates. A friend who is knowledgeable in the area of local politics gives you the following information about them. You find the choice difficult and are trying to decide which candidate ito vote for/not to vote for].

Candidate A:
Enjoys camping and other outdoor $79 \%$
activities
Is a local businessman
Was voted "Most Enthusiastic" in
high school
Has two children enrolled in
the local elementary school
Majored in history in college
Candidate B:
Served honorably as the vice
president of the council
last term
Organized a fund raiser to support
the local children's hospital
Was voted "Best Looking"
in high school
Has bragged about his
promiscuity in the past
Refused to disclose income tax
records despite repeated
requests

Based on the information above, which candidate would you decide [to vote for/not to vote for]?

When asked which candidate they would not vote for, an overwhelming majority of our subjects picked the enriched candidate. Clearly, this candidate's negative features outweighed most other considerations. These negative features also played an influential role in subjects" decision of which candidate to support. However, in line with compatibility, the enriched candidate's positive features appear to have loomed comparatively larger in the latter decision. In fact, Candidate B's chances of being elected were more than two and a half times greater when subjects were deciding whom to elect than when they were deciding whom to reject $(21 \%$ vs. $8 \%, z=3.68, p<$ $.001)$. As predicted, the enriched candidate's share of being elected and rejected exceeds $100(z=2.31, p<.02)$.

\section{Nonbinary Problems}

The logic that characterizes the analyses above is not limited to binary choices. When presented with a larger set of alternatives, we are generally expected to exhibit a similar preference ranking regardless of whether we choose the alternatives starting with the best and ending at the worst, or reject them starting at the worst and ending with the best. Coombs, Donnell, and Kirk (1978), for example, document similar rankings of three lotteries obtained by choice and by rejection. The lotteries used by these investigators, however, were unlikely to yield the kind of compatibility effects documented above. The lotteries in their choice set differed (in a deliberately complicated fashion) in the exact distribution of prizes and the probability of winning, but they all provided the same potential amount loss, as well as the same expected gain. In order to document choose-reject discrepancies in nonbinary choices, we resort to our earlier strategy of offering subjects an assortment of enriched and impoverished options. Consider, for example, the following three lotteries.

\section{Problem 8}

Lottery 1: You have a $\mathbf{5 0 \%}$ chance to win $\$ \mathbf{5 0}$, otherwise nothing.

Lottery 2: You have a $60 \%$ chance to win $\$ 40$, otherwise nothing.

Lottery 3: You have an $80 \%$ chance to win $\$ 150$, and a $20 \%$ chance to lose $\$ 20$.

Half the subjects were asked to choose a lottery; the other half were asked to reject one lottery, and then to reject a second lottery (from the remaining two). According to classical theory, when we present people with three options, it should make no difference whether we ask them to choose one or to reject two. If, when asked to indicate their preferred lottery, a proportion equal to $\Pi_{c}$ of the subjects should choose Lottery 3 , then exactly $1-\Pi_{c}$ of the subjects are expected to include Lottery 3 among the two that they reject. ${ }^{6}$ Instead, Lottery 3 -the lottery offering by far the largest gain as well as the only lottery to provide a potential loss-was chosen by $61 \%$ of those who were asked to choose their preferred lottery, and rejected by $56 \%$ of those who were asked to reject the two that they preferred less $(N=139, z=2.0, p<.05)$. It was, in other words, chosen by the majority of choosers, and rejected by the majority of rejecters.

\section{Choice Sets and Framing}

Whether we find ourselves choosing or rejecting may sometimes depend on the particular choice sets under consideration. Imagine, for example, having to recommend one applicant from a pool of six or, alternatively, having to recommend five applicants from the same pool. Whereas the former task involves the selection of a candidate, the latter is likely to be framed as requiring the rejection of one candidate. The chances of enriched candidates are predicted to be better in the former rather than the latter scenario. To explore this prediction, subjects were presented with a set of six lotteries, three offering only a modest gain (hence, impoverished) and three offering a more substantial gain as well as a chance at a loss (hence, enriched). With the notation $(\$ 150, .65,-\$ 20)$ indicating a lottery that offers a $65 \%$ chance to win $\$ 150$, or otherwise to lose $\$ 20$, the six lotteries appear in the first column of Table 1. (By convention, the enriched lot- 
teries appear last, but the lotteries were presented to the subjects in alternating order.)

The subjects were asked to imagine that they would eventually get to play one of the six lotteries. One group of subjects $(n=62)$ was asked to choose their preferred lottery, another group $(n=63)$ was asked to reject their least preferred, a third group $(n=61)$ was asked to choose their five preferred lotteries, and a fourth group $(n=61)$ was asked to reject their five least preferred. These are summarized, respectively, in columns 2-5 of Table 1 . The left-hand numbers indicate the percentage of subjects who chose each lottery when the task was to choose, or (in parentheses) the percentage of subjects who failed to reject the lottery when the task was to reject. Similarly, the right-hand numbers show the percentage of subjects who rejected the lottery when the task was to reject, or (in parentheses) the percentage of subjects who failed to choose it when the task was to choose.

First, in line with our earlier findings, note that a majority of subjects chose an enriched lottery as their most preferred and a majority also rejected an enriched lottery as their least preferred $(53 \%$ and $76 \%$, in the second and third columns, respectively). ${ }^{7}$ Of more interest in the present context, however, is the comparison between the Choose 1 and Reject 1 and the Choose 5 and Reject 5 tasks. To the extent that subjects are expected to adopt a consistent frame whenever they are asked to choose among lotteries and whenever they are asked to reject among lotteries, we may expect a high correlation between the preference rankings obtained when one and when five lotteries are chosen (columns 2 and 4) and, similarly, when one and when five lotteries are rejected (columns 3 and 5). Instead, the observed correlations were quite low (rank correlation coefficients for columns 2 and 4 , and for columns 3 and 5 , are .43 and .09 , respectively, $p>.05$ in both cases). If, on the other hand, the instructions to choose five lotteries are converted by subjects into the task of rejecting one and, conversely, the request to reject five is converted into the task of choosing one, a high correlation should be observed between the rankings obtained via the Choose 1 and Reject 5 instructions and, similarly, between the Reject 1 and Choose 5 tasks. In- deed, the rank correlation coefficients for these conditions are 1.0 and .89 , respectively ( $p<.05$ in both cases).

The data suggest that having to choose five out of six options is converted by subjects into the simpler task of rejecting a single option. Conversely, the task of rejecting five out of six options is converted into the more natural task of choosing one alternative. Choice, according to compatibility, is expected to give enriched options an advantage over rejection. Indeed, while in the Reject 1 condition the three most frequently rejected options were enriched options, in the Reject 5 condition (which apparently is converted into a Choose 1 task) two of the three most frequently rejected options were impoverished options. Similarly, two enriched options were among the three most frequently chosen in the Choose 1 condition, but only one was among the three most frequently chosen in the Choose 5 (which becomes a Reject 1) condition. Observe that, unlike the results of earlier demonstrations in which subjects were explicitly instructed to choose or to reject, the present choose-reject discrepancies arose out of subjects' own formulation of the problems, which were a function of the particular set sizes under consideration, not of explicit instructions. When a majority of options need to be chosen, the task is naturally seen as involving the rejection of the weakest; when a majority are to be rejected, the task is seen as involving the choice of a select few. The former, which according to the principle of compatibility focuses subjects' attention on weaknesses, improves the chances of the impoverished options, whereas the latter, which raises the relative weight of positive dimensions, favors the enriched alternatives.

\section{CONCLUDING REMARKS}

Perhaps the most basic assumption of the rational theory of choice is the principle of procedure invariance, which requires strategically equivalent methods of elicitation to yield the same preference order. However, empirical tests of procedure invariance have shown it to fail in a systematic and predictable manner. For example, asking people to choose between two lotteries or, alternatively, asking them to state their price for each of these

Table 1 Percentages of Subjects Who Chose/Rejected Each Lottery in Each of Four Tasks

\begin{tabular}{|c|c|c|c|c|}
\hline Lotteries & $\begin{array}{l}\text { Choose } 1 \\
(n=62)\end{array}$ & $\begin{array}{c}\text { Reject } 1 \\
(n=63)\end{array}$ & $\begin{array}{l}\text { Choose } 5 \\
(n=61)\end{array}$ & $\begin{array}{l}\text { Reject } 5 \\
(n=61)\end{array}$ \\
\hline \multicolumn{5}{|c|}{ Impoverished } \\
\hline $\begin{array}{l}1(\$ 75, .50,0) \\
2(\$ 55, .60,0) \\
3(\$ 45, .75,0)\end{array}$ & $\begin{array}{r}11 /(89) \\
3 /(97) \\
32 /(68)\end{array}$ & $\begin{array}{l}(98) / 2 \\
(86) / 14 \\
(92) / 8\end{array}$ & $\begin{array}{l}92 /(8) \\
82 /(18) \\
87 /(13)\end{array}$ & $\begin{array}{r}(10) / 90 \\
(5) / 95 \\
(33) / 67\end{array}$ \\
\hline \multicolumn{5}{|c|}{ Enriched } \\
\hline $\begin{array}{l}4(\$ 130, .80,-\$ 35) \\
5(\$ 150, .65,-\$ 20) \\
6(\$ 120, .50,-\$ 10)\end{array}$ & $\begin{array}{r}24 /(76) \\
8 /(92) \\
21 /(79)\end{array}$ & $\begin{array}{l}(76) / 24 \\
(75) / 25 \\
(73) / 27\end{array}$ & $\begin{array}{l}85 /(15) \\
74 /(26) \\
80 /(20)\end{array}$ & $\begin{array}{r}(31) / 69 \\
(7) / 93 \\
(15) / 85\end{array}$ \\
\hline
\end{tabular}

Note-The left-hand numbers are the percentages of subjects who chose the lottery when the task was to choose, or (in parentheses) the percentages of subjects who did not reject the lottery when the task was to reject. The right-hand numbers show the complementary rejection rates. 
lotteries often leads to a different preference order: the monetary payoffs of lotteries weigh more heavily in setting a (monetary) price than in choosing, and the relative prominence of the chance to win looms larger when one is making a choice than when one is setting a price. The present findings follow a similar logic: advantages are weighted more heavily in choosing than in rejecting, and disadvantages weigh more heavily in rejecting than in choosing. Notice, however, that while the ordinal method of choice and the cardinal method of pricing differ in response scale and are likely to involve different cognitive mechanisms, choosing and rejecting are commonly regarded as two equivalent methods of arriving at the same ordinal scale. If we compare the assessment of preference to the measurement of mass, we can think of choice versus pricing as corresponding to the use of a pan balance versus a spring. Choosing versus rejecting, on the other hand, is like using the pan balance to see which option sinks lower or, alternatively, to see which option rises higher.

Our intuition is to treat choosing and rejecting as perfectly interchangeable. Often, when we find it hard to make a selection (say, on a menu), we decide to "first eliminate those options that we do not want." Of course, with some options this is a safe procedure-one may strongly dislike spinach and would not order it no matter what method one used. When presented with choice problems in which one option dominates (e.g., is better on all dimensions than) another, people choose the dominating option and reject the dominated one. Often, however, preferences among the options that remain after the strictly weaker ones have been discarded are less clear. As the present findings illustrate, in some cases one may end up choosing an option one otherwise would have rejected. In a study of personnel selection decisions, Huber, Neale, \& Northcraft (1987) presented subjects with actual resumés and letters of application received by a firm in response to an advertisement in a local newspaper, and asked them either to list the names of all the applicants that they would accept for an interview or to list those that they would reject. Huber et al. found that significantly more candidates were chosen for the job interview under the rejection frame than under the acceptance frame. Although these authors interpret their findings in terms of the risk attitudes induced by the different tasks, it is possible that a contributing factor is the type of information available. Resumés are likely to be inherently biased toward candidates' strengths, with few weaknesses explicitly provided. When deciding which candidates to accept, subjects choose those with the most impressive qualities, but when rejecting candidates, hence focusing on their weaknesses, subjects may find little to go by and end up rejecting relatively few.

In certain circumstances, the focus on positive or negative features may be induced by the semantics of a question posed by an experimenter or an interviewer, whereas in other cases it may be self-induced. Consider, for example, the last time you chose between jobs, or between schools. Could it be that you focused too much on the reasons for choosing-namely, the positive aspects-and paid too little attention to the negative aspects that later seemed to bother you more than you thought they would? As discussed by Slovic et al. (1990), although compatibility can have a powerful effect on the expression of preference, people are generally unaware of this phenomenon, which seems to operate at an elementary level of information processing. It is doubtful, furthermore, whether the bias can be eliminated by careful instructions or monetary rewards, as is indicated by the failure of incentives to affect the prevalence of preference reversals (Slovic \& Lichtenstein, 1983).

Whether we end up choosing or rejecting may often be an accident of fate. Imagine that you plan to buy a rug, and come upon two rugs that you like: one-the impoverished rug-is simple and fairly priced; the otherthe enriched rug - is quite lovely but expensive. You can either choose one now, or take advantage of the store's offer to take both rugs home to decide. Whereas at the store you are in the process of choosing and may be tempted to opt for the more beautiful rug, at home you would be deciding which to return to the store, and might feel compelled to return the rug that you feel less able to afford. According to the present findings, all else being equal, you are more likely to end up with the enriched rug if you choose than if you return one. As illustrated above, the size of the set under consideration may also determine whether we end up choosing or rejecting. The need to recommend 2 applicants from a pool of 10 is likely to be seen as requiring the selection of 2 , whereas having to recommend 8 applicants from the same pool will most likely be framed as requiring the rejection of 2 . Relative to the chances of an impoverished candidate, those of an enriched candidate are predicted to be greater in the former than in the latter scenario. Finally, temporal considerations may also influence the perspective that we adopt. As pointed out by Bursztajn et al. (1991), clinicians make treatment decisions prospectively, with the hope of improving the patient's health, whereas judges hearing malpractice cases must address such decisions retrospectively, after a harm has occurred. Thus, the courts tend to be more attuned to the potential harms of the treatment than to its benefits, relative to the doctors whose main concern are the potential benefits despite the risk of harm. One possible implication of this disparity is a greater propensity on the part of doctors to choose enriched treatments-ones that promise a variety of potential improvements-and a greater tendency on the part of the courts to find fault with the very same treatments, because of their more numerous potential harms.

In a study concerning the perceived consequences of risky behaviors, Beyth-Marom, Austin, Fischhoff, Palmgren, and Jacobs-Quadrel (in press) found persistent asymmetries in the perceived consequences of accepting and rejecting a risky action. Among other things, they found that the thought of taking a risky action produced four times as many bad consequences as it produced good consequences, whereas the thought of not taking that action yielded roughly equal numbers of good and bad conse- 
quences. Because of such asymmetries, these authors suggest, it may be hard to understand people's tendency to take certain actions if one fails to elicit the perceptions associated with not taking those actions. For example, considerations such as "being liked by friends" or "feeling more grown up" appear to be less salient when youths consider using marijuana than when they consider declining it.

We generally tend to think of our decisions in terms of choosing rather than rejecting. Interestingly, the greater popularity of the choose formulation (the "unmarked" form) implies that the instructions to reject may ultimately result in a less "biased" weighing of dimensions: asked to reject, a considerable proportion of people nonetheless entertain the act of choosing, whereas, asked to choose, few consider the alternative act of rejecting. This raises the possibility that when inquiring about preferences (in experiments, or surveys), we may want to consider using the less common reject rather than the more biased choose formulation or, better yet, some combination of the two. (For a related discussion of the mixing of mortality and survival frames in medical decision making, see McNeil, Pauker, \& Tversky, 1988.) Naturally, further theoretical analysis and empirical investigation will be required for researchers to clarify the nature of compatibility in general, and its role in choosing versus rejecting in particular.

The principle of compatibility has been used in the present paper to predict differential focusing on options' positive and negative aspects, which are assumed to provide compelling reasons for choice and for rejection, respectively. Naturally, compatibility is only one of a number of factors that may affect the determination of preference. Moreover, its influence is likely to be confined to choices among options between which it is otherwise hard to choose. Nonetheless, the notion that we reach our decisions by relying on options' positive and negative aspects, rather than overall subjective values, has a number of interesting implications. Keeping overall values roughly equal, options with more reasons for and against them are more likely to be selected, both as winners and as losers. Assume, for example, a competition for "athlete of the year," in which all the contestants are equally meritorious. If instead of relying on overall value we rely on reasons for choosing the winner, it is likely that athletes in areas about which we are more knowledgeable (e.g., basketball and baseball as opposed to javelin throwing and hang gliding) will present us with more reasons for picking them as winners. Of course, if we were looking to select the overall loser, athletes in these same sports would also provide us with most reasons for being picked as losers. Thus, athletes in the more popular sports will tend to be selected as athlete of the year, dogs of more popular kinds will tend to win the dog shows, and cars with more "features" in them will sell better. All this, even if the more impoverished competitors-those about whom less can be said-are equally deserving.

The preceding scenarios present us with the task of choosing the winner and, as a result, we are predicted to be biased towards the enriched options. In other situations, however, our main concern is to reject the losers, and then we are predicted to reward the impoverished alternatives. Consider, for example, the initial weeding out process conducted by selection committees. Or the workings of special interest groups, who often consider it their mission to oppose candidates who are particularly unattractive on certain dimensions. And assume a pool of contestants all of whom have their faults and their good qualities, but some of whom have more of both than others do. To the extent that committees and special interest groups, as well as regular voters, are strongly invested in eliminating the candidates whom they perceive as having significant faults (with less emphasis on what may be their good qualities), we are predicted to be left with the impoverished candidates, politicians, and judges-those who provide us with few reasons to oppose them. We are predicted, to borrow Robert Musil's words, to fill our government and our courts with men and women without (positive or negative) qualities. ${ }^{8}$

Like other framing and elicitation effects, the lability of preferences implied by the choosing-rejecting discrepancy raises difficult questions concerning the assessment of values and preferences. We typically think of people's choices as reflecting their underlying values. But if one option is both chosen over and rejected in favor of another, in what sense can we speak about subjective values? Are people's true preferences exhibited when they choose or when they reject? Because invariance is normatively indispensable, no normative theory of decision making can be reconciled with the present findings. More importantly, perhaps, these findings may not be easily reconcilable with our own intuitions. Next time we choose an option, we had better verify that it is not also the option we most want to reject. Of course, it just might be, which is why decisions are often so hard to make.

\section{REFERENCES}

BeLL, D. E. (1982). Regret in decision making under uncertainty. Operations Research, 30, 961-981.

Beyth-Marom, R., Austin, L., Fischhoff, B., Palmgren, C., \& JACOBS-QUADREL, M. (in press). Perceived consequences of risky behaviors: Adults and adolescents. Developmental Psychology.

Brainard, R. W., Irby, T. S., Fitts, P. M., Alluisi, E. (1962). Some variables influencing the rate of gain of information. Journal of Experimental Psychology, 63, 105-110.

Bursztajn, H., Chanowitz, B., Kaplan, E., Gutheil, T. G., Hamm, R. M., \& Alexander, V. (1991). Medical and judicial perceptions of the risks associated with use of antipsychotic medication. Bulletin of the American Academy of Psychology \& the Law, 19, 271-275.

CoOMBS, C. H., DonNell, M. L., \& KIRK, D. B. (1978). An experimental study of risk preference in lotteries. Joumal of Experimental Psychology: Human Perception \& Performance, 4, 497-512.

Dunning, D., \& Parpal, M. (1989). Mental addition versus subtraction in counterfactual reasoning: On assessing the impact of personal actions and life events. Journal of Personality \& Social Psychology, 57, 5-15.

FitTs, P. M., \& SEEGER, C. M. (1953). S-R compatibility: Spatial characteristics of stimulus and response codes. Joumal of Experimental Psychology, 46, 199-210.

GoLDSTEIN, W. M. (1990). Judgments of telative importance in decision making: Global vs local interpretations of subjective weight. $\mathrm{Or}$ ganizational Behavior \& Human Decision Processes, 47, 313-336. 
Houston, D. A., Sherman, S. J., \& Baker, S. M. (1989). The influence of unique features and direction of comparison on preferences. Joumal of Experimental Social Psychology, 25, 121-141.

Huber, V. L., Neale, M. A., \& NorthCraft, G. 8. (1987). Decision bias and personnel selection strategies. Organizational Behavior \& Human Decision Processes, 40, 136-147.

Kahneman, D., \& Snell, J. (1990). Predicting utility. In R. M. Hogarth (Ed.), Insights in decision making: A tribute to Hillel Einhom (pp. 295310). Chicago: University of Chicago Press.

Kornglum, S., Hasbrouce, T., a Osman, A. (1990). Dimensional overlap: Cognitive basis for stimulus-response compatibility-a model and taxonomy. Psychological Review, 97, 253-270.

Lichtenstein, S., \& SLovic, P. (1973). Response-induced reversals of preference in gambling: An extended replication in Las Vegas. Journal of Experimental Psychology, 101, 16-20.

LoOmes, G., SUGDEN, R. (1982). Regret theory: An alternative theory of rational choice under uncertainty. Economic Journal, 92 , 805-824.

LUCE, R. D. (1959). Individual choice behavior. New York: Wiley.

LUCE, R. D., SUPPES, P. (1965). Preference, utility, and subjective probability. In R. D. Luce, R. R. Bush, \& E. Galanter (Eds.), Handbook of mathematical psychology (pp. 249-410). New York: Wiley.

MARCH, J. (1978). Bounded rationality, ambiguity, and the engineering of choice. Bell Joumal of Economics, 9, 587-608.

MARLEY, A. A. I. (1968). Some probabilistic models of simple choice and ranking. Joumal of Mathematical Psychology, 5, 311-332.

McNeil, B. J., PAUker, S. G., \& Tversky, A. (1988). On the framing of medical decisions. In D. Bell, H. Raiffa, \& A. Tversky (Eds.), Decision making: Descriptive, normative, and prescriptive interactions (pp. 562-568). New York: Cambridge University Press.

Medin, D. L., Goldstone, R. L., \& GenTNER, D. (1990). Similarity involving attributes and relations: Judgments of similarity and difference are not inverses. Psychological Science, 1, 64-69.

Mueller, D. C. (1989). Public choice II. New York: Cambridge University Press.

PAYNe, J. W. (1982). Contingent decision behavior. Psychological Bulletin, $92,382-402$.

Proctor, R. W., \& Reeve, T. G. (Eds.) (1990). Stimulus-response compatibility: An integrated perspective. Amsterdam: North-Holland.

SChKade, D. A., Johnson, E. J. (1989). Cognitive processes in preference reversals. Organizational Behavior \& Human Decision Processes, 44, 203-231.

ShafiR, E., Simonson, I., \& Tversky, A. (in press). Reason-based choice. Cognition.

Simonson, I. (1989). Choice based on reasons: The case of attraction and compromise effects. Joumal of Consumer Research, 16, 158-174.

SLovic, P. (1990). Choice. In D. Osherson \& E. Smith (Eds.), An invitation to cognitive science: Vol. 3 (pp. 89-116). Cambridge, MA: MIT Press.

SLovic, P., FischHoff, B., \& Lichtenstein, S. (1982). Response mode, framing, and information-processing effects in risk assessment. In R. Hogarth (Ed.), New directions for methodology of social and be havioral science: Question framing and response consistency (pp. 21 36). San Francisco: Jossey-Bass.

Slovic, P., Grifrin, D., Tversky, A. (1990). Compatibility effects in judgment and choice. In R. Hogarth (Ed.), Insights in decision making: Theory and applications (pp. 5-27). Chicago: University of Chicago Press.

Slovic, P., \& Lichtenstein, S. (1983). Preference reversals: A broader perspective. American Economic Review, 73, 596-605.

TVERSKY, A. (1972). Elimination by aspects: A theory of choice. Psychological Review, 79, 281-299.

TVersky, A. (1977). Features of similarity. Psychological Review, 84, 327-352.

TVersky, A., \& GATI, I. (1978). Studies of similarity. In E. Rosch \& B. Lloyd (Eds.), Cognition and categorization (pp. 79-98). Hillsdale, NJ: Erlbaum.

TVersky, A., Kahneman, D. (1986). Rational choice and the framing of decisions. Journal of Business, 59, 251-278.

TVERSKY, A., KaHNEMAN, D. (1991). Loss aversion in riskless choice: A reference dependent model. Quarterly Journal of Economics, 107, 1039-1061.
Tversky, A., Sattath, S., \& Slovic, P. (1988). Contingent weighting in judgment and choice. Psychological Review, 95, 371-384.

TVersky, A., Shafir, E. (1992). The disjunction effect in choice under uncertainty. Psychological Science, 3, 305-309.

Tversky, A., Slovic, P., \& Kahneman, D. (1990). The causes of preference reversal. American Economic Review, 80, 204-217.

Viscusi, W. K., Magat, W. A., \&uber, J. (1987). An investigation of the rationality of consumer valuations of multiple health risks. Rand Journal of Economics, 18, 465-479.

von Neumann, J., Morgenstern, O. (1947). Theory of games and economic behavior. Princeton, NJ: Princeton University Press.

WICKENS, C. D. (1984). Engineering psychology and human performance. Columbus, $\mathrm{OH}$ : Merrill.

\section{NOTES}

1. For another study of choice guided by intuitions of the contrast model, see Houston, Sherman, and Baker (1989). See also Dunning and Parpal (1989) for related phenomena in counterfactual reasoning.

2. Note that, compatibility notwithstanding, a majority of students preferred to take Course $Y$ in both conditions. The compatibility prediction, which is about individual preference, does not require that the group be inclined to choose and reject the enriched option; it only asserts that individual members will. The influence of compatibility at the individual level is implied whenever the enriched option's share of choice and rejection exceeds $100 \%$. Of course, for any particular problem, the greater the number of individuals who show the effect, the more likely is majority preference to reverse as well.

3. It is interesting, however, that the coefficient of loss aversion could vary across dimensions (see Tversky \& Kahneman, 1991), thereby potentially yielding choose-reject discrepancies in special cases. Thus, for example, because loss aversion appears to be more pronounced for safety than for money (Viscusi, Magat, \& Huber, 1987), there could arise instances wherein we value money more than safety while choosing, but safety more than money when giving an option up.

4. It could be argued that the anticipated regret of not winning constitutes an unattractive dimension of the first lottery. People, however, balk at the request to rate this lottery's unattractiveness, claiming that there is nothing unattractive about it. This argues against the assumption that anticipated regret constitutes a significant dimension of (at least, modest) probabilistic gains.

5. This problem was conducted in collaboration with Howard Neuthaler.

6. For models that predict imperfect reversed rankings- while nonetheless adhering to this relatively weak claim-see Luce, 1959, and Luce and Suppes, 1965; see also Marley, 1968, for a related discussion. It is interesting that an extension of Tversky's (1972) elimination-by-aspects model to include both advantages and disadvantages, and hence both choosing and rejecting, could also predict discrepant rankings.

7. Note that in the present context a majority choice and rejection of enriched options need not necessarily imply nonnormative behavior: subjects could be choosing one enriched option, while rejecting another. A scrutiny of the distributions in Table 1 , however, reveals comparable popularity for the various options (all three enriched lotteries, for example, were rejected equally often), which does not support this interpretation.

8. In this vein, Yale Law School dean Guido Calabresi (New York Times, Op-Ed, July 28, 1991) bemoans the strong resistance to the appointment of a Supreme Court judge with whose views he happens strongly to disagree. At least, laments Calabresi, the judge is a man "who does stand out, who holds ... his views. Instead, like many times before, the papers and eminent scholars will join the bandwagon of support for the nonentity. For in such a person the 'offending' views will not stand out against the grayness of his background." A similar view is expressed by Sir Henry Sumner Maine (as quoted in Mueller, 1989): "a candidate for the Presidency, nominated for election by the whole people, will, as a rule, be a man selected because he is not open to obvious criticism, and will therefore in all probability be a mediocrity."

(Manuscript received January 21, 1992; revision accepted for publication February 2, 1993.) 